Mathematical Supplement to Accompany

COMPETITION, MONOPOLY MAINTENANCE,

AND CONSUMER SWITCHING COSTS

\author{
by \\ Hodaka Morita \\ School of Economics, Australian School of Business \\ University of New South Wales \\ Sydney 2052, Australia \\ (61-2) 9385-3341,h.morita@unsw.edu.au \\ and \\ Michael Waldman \\ Johnson Graduate School of Management \\ Cornell University \\ Sage Hall \\ Ithaca, NY 14853 \\ (607) 255-8631,mw46@cornell.edu
}




\section{A detailed analysis of the benchmark case}

First, as a benchmark analysis, suppose the maintenance market is competitive and each durablegoods producer can commit in the first period to the prices it will charge in subsequent periods for a new unit of output. Let $\mathrm{P}_{\mathrm{jtk}} *$ denote the price that producer $\mathrm{j}$ charges in this case for a new unit of output in period t to group $\mathrm{k}, \mathrm{k}=1,2$, or 3 , consumers. We find that there exist values $\mathrm{v}_{\mathrm{L}} *, 0<\mathrm{v}_{\mathrm{L}} *<\mathrm{V}$, and $\mathrm{m}^{*}$, $0<\mathrm{m}^{*}<\infty$, such that the following describes the equilibrium. First, each producer $\mathrm{j}$ chooses $\mathrm{P}_{\mathrm{jt} 1} *=\mathrm{P}_{\mathrm{jt} 2} *=\mathrm{P}_{\mathrm{jt} 3} *=\mathrm{c}$ for all $\mathrm{t}, \mathrm{t}=1,2, \ldots \infty$. Second, every consumer $\mathrm{i}$ born in period $\mathrm{t}, \mathrm{t}=1,2, \ldots \infty$, for whom $\mathrm{v}_{\mathrm{i}}>\mathrm{V}_{\mathrm{L}} *$ purchases a new unit in period $\mathrm{t}$ and a new unit from firm $\mathrm{j}_{\mathrm{it}}$ in every period $\mathrm{t}^{\prime}, \mathrm{t}^{\prime}=\mathrm{t}, \mathrm{t}+1, \ldots \infty$, in which the consumer does not own a used unit at the beginning of the period, while consumers born in $t$ for whom $\mathrm{v}_{\mathrm{i}} \leq \mathrm{v}_{\mathrm{L}} *$ never purchase new units. Third, in any period $\mathrm{t}$ in which consumer $\mathrm{i}$ owns a used unit at the beginning of the period, the consumer maintains the unit if $m_{i t}{ }^{U} \leq m^{*}$ and purchases a new unit if $m_{i t}{ }^{U}>m^{*}$. Fourth, in any period $t$ in which individual i consumes a used unit the individual purchases $m_{i t}{ }^{U}$ units of maintenance.

An important feature of the above equilibrium is that $\mathrm{P}_{\mathrm{j} 11} *=\mathrm{P}_{\mathrm{jt} 2} *=\mathrm{P}_{\mathrm{jt} 3} *=\mathrm{c}$ for all t, i.e., all units in all periods are sold at a price equal to c. The logic behind this result is as follows. Consider the cohort of consumers born in the first period. Because it is a competitive market, durable-goods producer that sells a strictly positive number of new units to this cohort of consumers in the first period must market its product in the manner that minimizes the inefficiency associated with consuming the product. This means that each such firm commits to charge $\mathrm{c}$ for new units sold to these consumers in all subsequent periods. The reason is that, if maintenance and new units are both priced at marginal cost in all subsequent periods, the consumers will make efficient choices concerning who to purchase replacement units from and when to maintain rather than replace used units. Further, since the price for a new unit in each subsequent period is c, the zero-profit condition associated with perfect competition yields that the first-period price also equals c. In turn, repeating this argument for each cohort of consumers yields that all units in all periods are sold at a price equal to $\mathrm{c}$.

Given the durable-goods producers' equilibrium behavior described above, the corresponding consumer behavior in the equilibrium is the same as the optimal consumer behavior in the following hypothetical case: Suppose that no firms produce new units or perform maintenance. Instead, suppose that in each period each consumer i can produce a new unit and perform maintenance for her own consumption where the cost structure of maintenance is same as firms and the constant marginal cost of production for new units is c. In this hypothetical case, each consumer i's optimal behavior is as described in Lemma 1 below. In turn, Lemma 1 implies that the corresponding consumer behavior in the equilibrium is as described in the first paragraph of this section. 
Lemma 1: For the hypothetical case described above, there exist values $\mathrm{v}_{\mathrm{L}}^{*}, 0<\mathrm{v}_{\mathrm{L}}{ }^{*}<\mathrm{V}$, and $\mathrm{m}^{*}, 0<\mathrm{m}^{*}<\infty$, where $m^{*}(>0)$ is uniquely defined by $c-m^{*}=\beta \int_{0}^{m^{*}}\left(m^{*}-m\right) f(m) d m$ and $v_{L}^{*} \equiv m^{*}-\beta \Delta$ such that i) through iv) describe the equilibrium.

i) Every consumer i born in period $t$ for whom $v_{i}>v_{L} *$ consumes a new unit in period $t$, while each consumer i for whom $\mathrm{v}_{\mathrm{i}} \leq \mathrm{v}_{\mathrm{L}}$ * never consumes new units, used units, or maintenance.

ii) In each period $t^{\prime}, t^{\prime}>t$, each consumer $i$ born in period $t$ for whom $v_{i}>v_{L} *$ and who does not own a used unit at the beginning of the period consumes a new unit.

iii) In each period $t^{\prime}, t^{\prime}>t$, each consumer $i$ born in period $t$ who does own a used unit at the beginning of the period consumes a new unit if $\mathrm{m}_{\mathrm{it}} \mathrm{U}^{\mathrm{U}} \mathrm{m}^{*}$, consumes $\mathrm{m}_{\mathrm{it}}{ }^{\mathrm{U}}$ units of maintenance if $\mathrm{m}_{\mathrm{it}^{\prime}} \mathrm{U}^{\mathrm{u}}<\mathrm{m}^{*}$, and chooses one of these two behaviors if $\mathrm{m}_{\mathrm{it}^{\prime}} \mathrm{U}^{\mathrm{N}}=\mathrm{m}^{*}$.

iv) $\mathrm{EU}_{\mathrm{i}}{ }^{*}=\max \left\{\frac{1}{1-\beta}\left(\mathrm{v}_{\mathrm{i}}-\mathrm{v}_{\mathrm{L}}{ }^{*}\right), 0\right\}$ for each consumer $\mathrm{i}$.

\section{Proof of Lemma 1:}

Consider consumer $\mathrm{i}$ who is born in period t. Considering such a consumer who does not own a used unit at the beginning of a period and did not consume a unit in the previous period, we have (B1). We also have (B2) and (B3).

$$
\begin{aligned}
& \mathrm{EU}_{\mathrm{i}}^{*}=\max \left\{0+\beta \mathrm{EU}_{\mathrm{i}}^{*}, \mathrm{v}_{\mathrm{i}}-\mathrm{c}+\beta \mathrm{E}_{\mathrm{i}}\left(\mathrm{V}_{\mathrm{i}}^{\mathrm{U}}(\mathrm{m})\right)\right\} \\
& \mathrm{V}_{\mathrm{i}}^{\mathrm{U}}(\mathrm{m})=\max \left\{0+\beta \mathrm{EU}_{\mathrm{i}}^{*}, \mathrm{v}_{\mathrm{i}}+\Delta-\mathrm{m}+\beta \mathrm{V}_{\mathrm{i}}, \mathrm{v}_{\mathrm{i}}+\Delta-\mathrm{c}+\beta \mathrm{E}_{\mathrm{i}}\left(\mathrm{V}_{\mathrm{i}}^{\mathrm{U}}(\mathrm{m})\right)\right\} \\
& \mathrm{V}_{\mathrm{i}}=\max \left\{0+\beta \mathrm{EU}_{\mathrm{i}}^{*}, \mathrm{v}_{\mathrm{i}}+\Delta-\mathrm{c}+\beta \mathrm{E}_{\mathrm{i}}\left(\mathrm{V}_{\mathrm{i}}^{\mathrm{U}}(\mathrm{m})\right)\right\}
\end{aligned}
$$

Note that (B1) implies $\mathrm{EU}_{\mathrm{i}}{ }^{*} \geq \beta \mathrm{EU}_{\mathrm{i}}{ }^{*}$, which in turn implies $\mathrm{EU}_{\mathrm{i}}{ }^{*} \geq 0$ given $0<\beta<1$. First consider consumer $\mathrm{i}$ for whom $\mathrm{v}_{\mathrm{i}}-\mathrm{c}+\beta \mathrm{E}_{\mathrm{i}}\left(\mathrm{V}_{\mathrm{i}}^{\mathrm{U}}(\mathrm{m})\right) \leq \beta E \mathrm{U}_{\mathrm{i}}^{*}$ holds. This implies $\mathrm{v}_{\mathrm{i}}-\mathrm{c}+\beta \mathrm{E}_{\mathrm{i}}\left(\mathrm{V}_{\mathrm{i}}^{\mathrm{U}}(\mathrm{m})\right) \leq \mathrm{EU}_{\mathrm{i}}^{*}=0$, which in turn implies that such consumer i never consumes a unit.

Next consider consumer $i$ for whom $\mathrm{v}_{\mathrm{i}}-\mathrm{c}+\beta \mathrm{E}_{\mathrm{i}}\left(\mathrm{V}_{\mathrm{i}}^{\mathrm{U}}(\mathrm{m})\right)>\beta E \mathrm{U}_{\mathrm{i}}^{*}$ holds. Then, since $\mathrm{v}_{\mathrm{i}}+\Delta-$ $\mathrm{c}+\beta \mathrm{E}_{\mathrm{i}}\left(\mathrm{V}_{\mathrm{i}}^{\mathrm{U}}(\mathrm{m})\right)>\beta E \mathrm{U}_{\mathrm{i}}$ * holds, (B2) and (B3) together imply that consumer $\mathrm{i}$ born in period $\mathrm{t}$ consumes a unit in every period $t^{\prime}=t, t+1, \ldots \infty$. Hence, the present discounted value evaluated in period $t$ of the gross benefits received by consumer i is $[1 /(1-\beta)]\left(v_{i}+\beta \Delta\right)$. In each period, consumer i makes her replacement/maintenance decision so as to minimize the present discounted value of future expected costs for consumption. Let $\mathrm{x}$ $\left(\mathrm{x}_{\mathrm{u}}(\mathrm{m})\right)$ denote the present discounted value of a consumer's future expected costs evaluated in a period when the consumer does not own a used unit (owns a used unit with $\mathrm{m}$ as the required level of maintenance) at the beginning of the period. We have (B4) and (B5). 


$$
\begin{gathered}
x_{u}(m)=\min \{m+\beta x, x\} \\
x=c+\beta \int_{0}^{\infty} \quad x_{u}(m) f(m) d m
\end{gathered}
$$

(B4) implies that there exists a value $m^{*}$ such that $x_{u}(m)=m+\beta x$ if $m \leq m^{*}$, and $m^{*}+\beta x$ if $m>m^{*}$. Then (B4) implies $m^{*}+\beta x=x$, and hence we have (B6).

$$
\mathrm{x}=\frac{m^{*}}{1-\beta} \text {. }
$$

We also have

$$
\int_{0}^{\infty} \mathrm{x}_{\mathrm{u}}(\mathrm{m}) \mathrm{f}(\mathrm{m}) \mathrm{dm}=\beta \mathrm{x}+\int_{0}^{m^{*}} m f(m) d m+\int_{m^{*}}^{\infty} m^{*} f(m) d m .
$$

Substituting this into (B5) and rearranging yield (B7).

$$
\mathrm{x}=\frac{1}{1-\beta^{2}}\left[c+\beta\left(\int_{0}^{m^{*}} m f(m) d m+\int_{m^{*}}^{\infty} m^{*} f(m) d m\right)\right] .
$$

Substituting (B6) into (B7) and rearranging yield (B8).

$$
\mathrm{c}-\mathrm{m} *=\beta \int_{0}^{m^{*}}(\mathrm{~m} *-\mathrm{m}) \mathrm{f}(\mathrm{m}) \mathrm{dm} .
$$

Define $\phi_{1}(\mathrm{y}) \equiv \mathrm{c}-\mathrm{y}$ and $\phi_{2}(\mathrm{y}) \equiv \beta \int_{0}^{y}(\mathrm{y}-\mathrm{m}) \mathrm{f}(\mathrm{m}) \mathrm{dm}$. Noting that $\phi_{1}(\mathrm{y})$ is continuous and strictly decreasing in $\mathrm{y}$ and $\phi_{2}(\mathrm{y})$ is continuous and strictly increasing in $\mathrm{y}$, there exists a unique value $\mathrm{m}^{*}>0$ such that equation (B8) holds. Hence, if consumer i owns a used unit in the beginning of period $t$, it performs maintenance for the used unit if and only if $\mathrm{m}_{\mathrm{it}} \mathrm{U}^{\mathrm{U}}$, where $\mathrm{m}^{*}>0$ is uniquely defined by (B8). Also, (B6) implies $\mathrm{EU}_{\mathrm{i}}^{*}=\frac{1}{1-\beta}\left(\mathrm{v}_{\mathrm{i}}+\beta \Delta-\mathrm{m}^{*}\right)$. This in turn implies that consumer $\mathrm{i}$ born in period $\mathrm{t}$ consumes a unit in every period $\mathrm{t}^{\prime}=\mathrm{t}, \mathrm{t}+1, \ldots \infty$ if $\mathrm{v}_{\mathrm{i}}>\mathrm{m}^{*}-\beta \Delta$, and consumer i never consumes a unit if $\mathrm{v}_{\mathrm{i}} \leq \mathrm{m}^{*}-\beta \Delta$. Hence i) through iv) describe the equilibrium of the hypothetical case for all consumers born in any period. Q.E.D.

\section{Supplement to the proof of Proposition 1}

Below we show that there does not exist an equilibrium that does not satisfy $0<\mathrm{v}_{\mathrm{L}}{ }^{*}<\mathrm{V}_{\mathrm{L}}{ }^{\mathrm{C}}, \mathrm{m}^{\mathrm{C}}>\mathrm{m} *$, and i) through v). Given the analysis presented in the appendix of the paper, it suffices to show that all newly-born consumers who participate in the durable-goods market purchase new units in their first period at a price $\mathrm{P}^{\prime}, \mathrm{c}-\Delta<\mathrm{P}^{\prime}<\mathrm{c}$. First, they could not all purchase at a price greater than or equal to $\mathrm{c}$ or at a price less than or equal to c- $\Delta$ because this would violate the zero-profit condition. Second, it could not be the case that in some periods newly born consumers purchase new units at $\mathrm{P}^{\prime}$ while in other periods they purchase at $\mathrm{P}^{\#}, \mathrm{P}^{\#} \neq \mathrm{P}^{\prime}$. This is because one of these prices would have to violate the zero-profit condition. Third, it could not be the case that there is a period in which some newly-born consumers purchase at $\mathrm{P}^{\prime}$ 
while others purchase at $\mathrm{P}^{\#}, \mathrm{P}^{\#} \neq \mathrm{P}^{\prime}$. The reason is that the prices these consumers would face in later periods would be independent of whether the initial unit was purchased at $\mathrm{P}^{\prime}$ or $\mathrm{P}^{\#}$, so all such consumers would choose the lower price. Fourth, for reasons stated earlier, it could not be the case that some consumers first purchase new units after their first period. Q.E.D.

\section{Supplement to the proof of Proposition 2}

In the appendix of the paper we have shown that the outcome described in Proposition 2 is an equilibrium outcome given Strategy Set M. Below we show that Strategy Set M constitutes an equilibrium set of strategies and that every equilibrium satisfies Strategy Set M. First, consider a firm in period $t$ for whom there are individuals that consumed a unit of the firm's product in the previous period and suppose all other firms employ the strategies described in Strategy Set M. Given the strategies of the other firms and assuming the consumer best responses described above, the firm cannot earn strictly positive profits from selling to consumers who did not consume a unit of the firm's product in the previous period. In turn, given this, the firm will achieve the highest possible profits starting in period $t$ if it earns zero profits from this set of consumers and extracts all the potential surplus from the consumers who consumed a unit of the firm's product in the previous period. By the latter we mean each such consumer must be indifferent between purchasing from the firm and purchasing from another firm in period $t$ and all later periods and each such consumer must behave in an efficient fashion in period $t$ and all later periods. Since following the strategy described in Strategy M satisfies this given the consumer best responses described above, this strategy must be a best response.

Second, consider a firm in period $t$ for whom there are not individuals who consumed a unit of the firm's product in the previous period, and suppose that all other firms employ the strategies described in Strategy Set M. Given the strategies of the other firms and assuming the consumer best responses described above, the firm cannot earn strictly positive profits from selling to any group of consumers this period. In turn, given this, a best response is any strategy that earns zero expected profits starting in period t. Since from above we know that if the firm sells new units this period it will not have an incentive to deviate from the strategy described in Strategy Set M in later periods, following the strategy described in Strategy Set $\mathrm{M}$ this period must be a best response.

Finally, consider a firm in period $t$ for whom there are no individuals who consumed a unit of the firm's product in any past period and suppose that all other firms employ the strategies described in Strategy Set M. Then, given the strategies of the other firms and assuming the consumer best responses described above, the firm cannot earn strictly positive profits from selling a strictly positive amount of output this period. In turn, given this, a best response is any strategy that earns zero expected profits starting in period 1. Since from the analysis presented in the previous paragraph we know that if the firm 
sells new units this period it will not have an incentive to deviate from the strategy described in Strategy Set $\mathrm{M}$ in later periods, following the strategy described in Strategy Set M this period must be a best response. Hence, Strategy Set M constitutes an equilibrium set of strategies.

We now show that every equilibrium satisfies Strategy Set M. Through a procedure similar to the one presented in the proof of Proposition 4 in the paper, it can be shown that there does not exist an equilibrium in which a firm does not monopolize its maintenance market and sells a strictly positive amount of units. Given this, let $\mathrm{P}_{\mathrm{t}}^{+}$denote the price at which consumers born in period t purchase a new unit in period $\mathrm{t}$ in the equilibrium. The zero profit condition implies that $\mathrm{P}_{\mathrm{t}}{ }^{+} \leq \mathrm{c}$ for all $\mathrm{t}$. This in turn implies that in every period $t$, in the equilibrium every firm $\mathrm{j}$ that sold new units in the previous period chooses prices such that $\mathrm{P}_{\mathrm{jt} 1}{ }^{\mathrm{M}}=\mathrm{P}_{\mathrm{t}}^{+}$and $\mathrm{P}_{\mathrm{jt} 2}{ }^{\mathrm{M}}=\mathrm{P}_{\mathrm{jt} 3}{ }^{\mathrm{M}}=\mathrm{P}_{\mathrm{t}}^{+}+\Delta$, and $\mathrm{p}_{\mathrm{jt}} \mathrm{U}(\mathrm{m})=\mathrm{P}_{\mathrm{t}}^{+}+\Delta$ for all $\mathrm{m}<\mathrm{m}^{*}, \mathrm{p}_{\mathrm{jt}}{ }^{\mathrm{U}}(\mathrm{m})>\mathrm{P}_{\mathrm{t}}^{+}+\Delta$ for all $\mathrm{m}>\mathrm{m}^{*}$, and $\mathrm{p}_{\mathrm{jt}} \mathrm{U}^{\mathrm{U}}(\mathrm{m}) \geq \mathrm{P}_{\mathrm{t}}^{+}+\Delta$ for $\mathrm{m}=\mathrm{m}^{*}$. The zero profit condition then implies that $\mathrm{P}_{1}{ }^{+}=\ldots=\mathrm{P}_{\infty}{ }^{+} \equiv \mathrm{P}^{+}<\mathrm{c}$. This implies that every equilibrium satisfies Strategy Set M. Q.E.D.

\section{Supplement to the proof of Proposition 3}

We first analyze the following hypothetical case: Suppose that no firms produce new units or perform maintenance. Instead, suppose that each consumer i chooses a certain level of durability when the consumer is age 1 , and in each period can produce a new unit with the chosen level of durability and perform maintenance for her own consumption, where the cost structures of production and maintenance are the same as those of firms described above. In this hypothetical case, each consumer i's optimal behavior is as described in Lemma 2 below.

Lemma 2: For the hypothetical case described above, there exist values $\mathrm{v}_{\mathrm{L}}^{*}>0, \mathrm{~d}^{*}>0$, and $\mathrm{q}^{*}>0$, where $\mathrm{v}_{\mathrm{L}} * \equiv \mathrm{m}^{*}-\beta \Delta$ and $\mathrm{m}^{*} \equiv \mathrm{q}^{*} /\left(1+\mathrm{d}^{*}\right)$ such that i) through iii) describe the equilibrium.

i) Every consumer $\mathrm{i}$ born in period $\mathrm{t}$ for whom $\mathrm{v}_{\mathrm{i}}>\mathrm{v}_{\mathrm{L}} *\left(\mathrm{v}_{\mathrm{i}} \leq \mathrm{v}_{\mathrm{L}} *\right)$ consumes a new unit with the durability level $\mathrm{d}^{*}$ in period $\mathrm{t}$ (never consumes new units, used units, or maintenance).

ii) In each period $t^{\prime}, t^{\prime}>t$, each consumer $i$ born in period $t$ for whom $v_{i}>v_{L} *$ and who does not own a used unit at the beginning of the period consumes a new unit.

iii) In each period $t^{\prime}, t^{\prime}>t$, each consumer $i$ born in period $t$ who does own a used unit at the beginning of the period consumes a new unit if $\mathrm{m}_{\mathrm{it}^{\prime}}{ }^{\mathrm{U}}>\mathrm{m}^{*}$, consumes $\mathrm{m}_{\mathrm{it}} \mathrm{U}^{\mathrm{U}}$ units of maintenance if $\mathrm{m}_{\mathrm{it}^{\prime}} \mathrm{U}^{\mathrm{U}}<\mathrm{m}^{*}$, and chooses one of these two behaviors if $\mathrm{m}_{\mathrm{it}} \mathrm{U}^{\mathrm{U}}=\mathrm{m}^{*}$.

Proof of Lemma 2: First note that, through a procedure analogous to the one in the proof of Lemma 1 above, we have that every consumer born in period $t$ either consumes a unit in every period $t^{\prime}=t, t+1, \ldots \infty$, or never consumes a unit. Consider consumer $\mathrm{i}$ who was born in period $\mathrm{t}$ and consumes a unit in every period 
$t^{\prime}=t, t+1, \ldots \infty$. The present discounted value evaluated in period $t$ of the gross benefits received by consumer $i$ is $[1 /(1-\beta)]\left(v_{i}+\beta \Delta\right)$. Suppose that consumer i chose $d(>0)$ in period $t$. Then, in each period consumer $i$ makes her replacement/maintenance decision so as to minimize the present discounted value of future expected costs for consumption. Let $\mathrm{x}\left(\mathrm{x}_{\mathrm{u}}(\mathrm{q})\right)$ denote the present discounted value of consumer i's future expected costs in period $t^{\prime}>t$ when the consumer does not own a used unit (owns a used unit with $q$ as the realization of the random variable) at the beginning of the period. We have (B9) and (B10).

$$
\begin{aligned}
& x_{u}(q)=\min \{[q /(1+d)]+\beta x, x\} . \\
& x=c+s(d)+\beta \int_{0}^{\infty} x_{u}(q) k(q) d q .
\end{aligned}
$$

(B9) implies that there exists a value $\mathrm{q}^{*}(>0)$ such that $\mathrm{x}_{\mathrm{u}}(\mathrm{q})=[\mathrm{q} /(1+\mathrm{d})]+\beta \mathrm{x}$ if $\mathrm{q} \leq \mathrm{q}^{*}$, and $\left[\mathrm{q}^{*} /(1+\mathrm{d})\right]+\beta \mathrm{x}$ if $\mathrm{q}>\mathrm{q}^{*}$. Then (B9) implies $\left[\mathrm{q}^{*} /(1+\mathrm{d})\right]+\beta \mathrm{x}=\mathrm{x}$, and hence we have (B11).

$$
\mathrm{x}=\frac{q^{*}}{(1-\beta)(1+d)} .
$$

We also have

$$
\int_{0}^{\infty} \mathrm{x}_{\mathrm{u}}(\mathrm{q}) \mathrm{k}(\mathrm{q}) \mathrm{dq}=\beta \mathrm{x}+\int_{0}^{q^{*}} \frac{q}{1+d} k(q) d q+\int_{q^{*}}^{\infty} \frac{q^{*}}{1+d} k(q) d q .
$$

Substituting this into (B10) and rearranging yield (B12).

$$
\mathrm{x}=\frac{1}{1-\beta^{2}}\left[c+s(d)+\beta\left(\int_{0}^{q^{*}} \frac{q}{1+d} k(q) d q+\int_{q^{*}}^{\infty} \frac{q^{*}}{1+d} k(q) d q\right)\right] .
$$

Substituting (B11) into (B12) and rearranging yield (B13).

$$
\mathrm{c}+\mathrm{s}(\mathrm{d})-\left[\mathrm{q}^{*} /(1+\mathrm{d})\right]=\beta \int_{0}^{q^{*}} \frac{q^{*}-q}{1+d} k(q) d q .
$$

Define $\phi_{1}(\mathrm{y}, \mathrm{d}) \equiv \mathrm{c}+\mathrm{s}(\mathrm{d})-[\mathrm{y} /(1+\mathrm{d})]$ and $\phi_{2}(\mathrm{y}, \mathrm{d}) \equiv \beta \int_{0}^{y} \frac{y-q}{1+d} k(q) d q$. Note that, for any given $\mathrm{d}, \phi_{1}(\mathrm{y}, \mathrm{d})$ is continuous and strictly decreasing in y while $\phi_{2}(\mathrm{y}, \mathrm{d})$ is continuous and strictly increasing in $\mathrm{y}$. This implies that there exists a unique value $\mathrm{q}^{*}(\mathrm{~d})>0$ such that equation (B13) holds if and only if $\mathrm{q}^{*}=\mathrm{q}^{*}(\mathrm{~d})$. Furthermore, since $\phi_{1}(y, d)$ and $\phi_{2}(y, d)$ are both continuous in $d, q^{*}(d)$ is also continuous in $d$.

We then have that in the first period consumer i chooses a level of durability $\mathrm{d}^{*}$ such that $\mathrm{d}^{*}=\underset{\{d\}}{\arg \min } \frac{q^{*}(d)}{(1-\beta)(1+d)}$ subject to $\mathrm{d} \geq 0$. The minimization problem has a solution given $\mathrm{q}^{*}(\mathrm{~d})$ is continuous in $\mathrm{d}$. Also, $(\mathrm{B} 12)$ and $\mathrm{s}^{\prime}(0)=0$ together imply $\mathrm{d}^{*} \neq 0$. Note, given footnote 16 along with (B10) and (B11) we have that $\mathrm{d}^{*}$ is unique. We then find that, if consumer $\mathrm{i}$ owns a used unit in the beginning of period $\mathrm{t}^{\prime}$, it performs maintenance for the used unit if and only if $\mathrm{m}_{\mathrm{it}} \leq \mathrm{m}^{*}, m^{*} \equiv \frac{q^{*}\left(d^{*}\right)}{1+d^{*}}$. Q.E.D. 
Given above analysis, consider a benchmark case in which the maintenance market is competitive, each producer can commit in the first period to the prices it will charge in subsequent periods for a new unit of output, and the level of product durability is fixed at $d^{*}$. Then, the equilibrium of the benchmark case is the same as the one in the original model, where $\mathrm{c}$ is replaced by $\mathrm{c}+\mathrm{s}\left(\mathrm{d}^{*}\right)$.

Below we present a supplement to the first paragraph of the proof of Proposition 3 presented in the paper.

Supplement to the first paragraph of the proof of Proposition 3: Let us for now focus on a set of equilibria in which no firms commit to future prices. We define the following set of strategies as Strategy Set M. In this set of strategies every durable-goods producer $\mathrm{j}$ chooses $\mathrm{d}_{\mathrm{j}}=\mathrm{d}^{*}$ and monopolizes the maintenance market for its own product in every period $t, t \geq 1$. Also, prices are defined by $i$ ) (where $\mathrm{c}$ is substituted by $\mathrm{c}+\mathrm{s}\left(\mathrm{d}^{*}\right)$ ) and ii), where $\mathrm{P}^{+}$satisfies a zero-profit condition.

Define $\mathrm{f}($.$) by \mathrm{f}\left(\mathrm{q} /\left(1+\mathrm{d}^{*}\right)\right)=\mathrm{k}(\mathrm{q})$ for all $\mathrm{q} \in(0, \infty)$. Then, $\mathrm{m}^{\mathrm{U}} \equiv \mathrm{q} /\left(1+\mathrm{d}^{*}\right)$ is the realization of a random draw from the probability density function $\mathrm{f}\left(\right.$.), where $\mathrm{f}\left(\mathrm{m}^{\mathrm{U}}\right)>0$ for all $\mathrm{m}^{\mathrm{U}} \in(0, \infty)$. Then, through the same procedure as in the proof of Proposition 2 presented in the paper, it can be shown that the outcome described in Proposition 2 (where c in i) is substituted by $\mathrm{c}+\mathrm{s}\left(\mathrm{d}^{*}\right)$ ) is an equilibrium outcome given Strategy Set M.

We now show that Strategy Set $M$ constitutes an equilibrium set of strategies. Consider firm $j$ that starts its operation in period 1, and suppose that all other firms employ the strategies described in Strategy Set M. Furthermore, suppose that firm $\mathrm{j}$ in period 1 chooses $d_{j}$ and sells a strictly positive number of new units at the price of $\mathrm{P}^{+}$. Given the strategies of the other firms, in any period $\mathrm{t}^{\prime}, \mathrm{t}^{\prime}>1$, firm $\mathrm{j}$ cannot earn strictly positive profits from selling to consumers who did not consume a unit of firm $\mathrm{j}$ 's product in the previous period. In turn, given this, the firm will achieve the highest possible profits starting in period 1 if it earns zero profits from this set of consumers and extracts all the potential surplus from the consumer who consumed a unit of the firm's product in the previous period. By the latter we mean that each such consumer must be indifferent between purchasing from the firm and purchasing from another firm in any period $t^{\prime}, t^{\prime}>1$, and each consumer must behave in an efficient fashion in any period $t^{\prime}$. Then, the analysis of the hypothetical case presented above implies that the present discounted value evaluated in period 1 of firm $\mathrm{j}$ 's expected profit from a consumer who purchases a new unit from firm $\mathrm{j}$ in period $\mathrm{t}$ is given by $\frac{1}{1-\beta}\left(P^{+}+\beta \Delta-\frac{q^{*}\left(d_{j}\right)}{1+d_{j}}\right)$. The analysis of the hypothetical case then implies that firm $\mathrm{j}$ 's optimal choice is $\mathrm{d}_{\mathrm{j}}=\mathrm{d}^{*}$. In turn, given this, through the same procedure as in the proof of Proposition 2 it can be shown that Strategy Set M constitutes an equilibrium set of strategies, and that every equilibrium is characterized 
by i) through vi) of Proposition 2, where in each equilibrium every durable-goods producer chooses durability level $\mathrm{d}^{*}$ and monopolizes the maintenance market for its own product in every period $\mathrm{t}, \mathrm{t} \geq 1$.

\section{Supplement to the proof of Proposition 4}

We first analyze the following hypothetical case: Suppose that no firms produce new units, sell replacement parts, or perform maintenance. Instead, suppose that in each period each consumer i can produce a new unit and perform maintenance for his or her own consumption with the same cost structure characterized by $c_{s}$ and $c_{r}$. In this hypothetical case, each consumer i's optimal behavior is as described in Lemma 3, where $\mathrm{EU}_{\mathrm{i}}{ }^{*}$ denotes the present discounted value evaluated in the period the consumer $\mathrm{i}$ is born of the expected net benefits received by consumer $\mathrm{i}$ in the hypothetical case. Note, below we let $r_{i t}{ }^{U}$ denote the number of replacement parts required in period $t$ by the used unit consumed by individual $i$ in the previous period.

Lemma 3: For the hypothetical case described above, there exist values $\mathrm{v}_{\mathrm{L}}^{*}, 0<\mathrm{v}_{\mathrm{L}} *<\mathrm{V}$, and $\mathrm{r}^{*}, 0<\mathrm{r}^{*}<\infty$, where $\mathrm{r}^{*}$ is uniquely defined by $\mathrm{c}-\mathrm{r} * \mathrm{c}_{\mathrm{r}}=\beta \int_{0}^{r^{*}}\left(\mathrm{r}^{*}-\mathrm{r}\right) \mathrm{c}_{\mathrm{r}} \mathrm{h}(\mathrm{r}) \mathrm{dr}$ and $\mathrm{v}_{\mathrm{L} 1} *=\mathrm{v}_{\mathrm{L} 2} *=\ldots=\mathrm{v}_{\mathrm{L} \infty} * \equiv \mathrm{c}_{\mathrm{s}}+\mathrm{r}^{*} \mathrm{c}_{\mathrm{r}}-\beta \Delta$ such that i) through iv) describe the equilibrium.

i) Every consumer $\mathrm{i}$ born in period $\mathrm{t}$ for whom $\mathrm{v}_{\mathrm{i}}>\mathrm{v}_{\mathrm{L}}{ }^{*}$ consumes a new unit in period $\mathrm{t}$, while each consumer i for whom $\mathrm{v}_{\mathrm{i}} \leq \mathrm{v}_{\mathrm{L}}$ * never consumes new units, used units, or maintenance.

ii) In each period $t^{\prime}, t^{\prime}>t$, each consumer $i$ born in period $t$ for whom $v_{i}>v_{L} *$ and who does not own a used unit at the beginning of the period consumes a new unit.

iii) In each period $t^{\prime}, t^{\prime}>t$, each consumer $i$ born in period $t$ who does own a used unit at the beginning of the period consumes a new unit if $r_{i t^{\prime}}{ }^{\mathrm{U}} \mathrm{r}^{*}$, consumes one unit of service and $\mathrm{r}_{\mathrm{it}} \mathrm{U}$ units of replacement parts if $r_{i t^{\prime}}{ }^{\mathrm{U}}<r^{*}$, and chooses one of these two behaviors if $r_{i t^{\prime}}{ }^{\mathrm{U}}=\mathrm{r}^{*}$.

iv) $\mathrm{EU}_{\mathrm{i}}^{*}=\max \left\{\frac{1}{1-\beta}\left(\mathrm{v}_{\mathrm{i}}-\mathrm{v}_{\mathrm{Lt}}{ }^{*}\right), 0\right\}$ for each consumer $\mathrm{i}$.

Proof of Lemma 3: Let $\mathrm{m}^{\mathrm{U}} \equiv \mathrm{c}_{\mathrm{s}}+\mathrm{r}^{\mathrm{U}} \mathrm{c}_{\mathrm{r}}$. Also, define $\mathrm{f}($.$) by \mathrm{f}\left(\mathrm{c}_{\mathrm{s}}+\mathrm{r}^{\mathrm{U}} \mathrm{c}_{\mathrm{r}}\right)=h\left(\mathrm{r}^{\mathrm{U}}\right)$ for all $\mathrm{r}^{\mathrm{U}} \in(0, \infty)$ and $\mathrm{f}\left(\mathrm{c}_{\mathrm{s}}+\mathrm{r}^{\mathrm{U}} \mathrm{c}_{\mathrm{r}}\right)=0$ for all $\mathrm{r}^{\mathrm{U}}$ outside this interval, and define $\mathrm{r}^{*}$ by $\mathrm{m}^{*} \equiv \mathrm{c}_{\mathrm{s}}+\mathrm{r}^{*} \mathrm{c}_{\mathrm{r}}$. Then, the proof is analogous to the proof of Lemma 1 proved above, given that $\mathrm{m}_{\mathrm{it}} \mathrm{U}^{\mathrm{U}}<\mathrm{m}^{*} \Leftrightarrow \mathrm{r}_{\mathrm{it}} \mathrm{U}^{\mathrm{U}} \mathrm{r}^{*}$, and $\mathrm{c}-\mathrm{m}^{*}=\beta \int_{0}^{\mathrm{m}^{*}}\left(\mathrm{~m}^{*}-\mathrm{m}\right) \mathrm{f}(\mathrm{m}) \mathrm{dm} \Leftrightarrow$ $\mathrm{c}-\mathrm{r}^{*} \mathrm{c}_{\mathrm{r}}=\beta \int_{0}^{r^{*}}\left(\mathrm{r}^{*}-\mathrm{r}\right) \mathrm{c}_{\mathrm{r}} \mathrm{h}(\mathrm{r}) \mathrm{dr}$. Q.E.D. 
Given the above analysis, we consider the following benchmark case: Suppose each durable-goods producer sells replacement parts to alternative maintenance suppliers at the price of $c_{r}$, and each producer can commit in the first period to the prices it will charge in subsequent periods for a new unit of output. Define $\mathrm{P}_{\mathrm{jtk}} *(\mathrm{k}=1,2$, or 3$)$ as in the text. As in the benchmark case of the basic model, given the analysis of the hypothetical case presented above we have that the following describes the equilibrium. First, each producer $\mathrm{j}$ chooses $\mathrm{P}_{\mathrm{jt1}} *=\mathrm{P}_{\mathrm{jt} 2} *=\mathrm{P}_{\mathrm{jt} 3} *=\mathrm{c}$ for all $\mathrm{t}$. Second, every consumer $\mathrm{i}$ born in period $\mathrm{t}$ for whom $\mathrm{v}_{\mathrm{i}}>\mathrm{V}_{\mathrm{L}} *$ purchases a new unit in period $t$ and a new unit from firm $j_{i t}$ in every period $t^{\prime}, t^{\prime}=t, t+1, \ldots \infty$, in which the consumer does not own a used unit at the beginning of the period, while consumers born in $\mathrm{t}$ for whom $\mathrm{v}_{\mathrm{i}} \leq \mathrm{v}_{\mathrm{L}} *$ never purchases new units. Third, in any period $\mathrm{t}$ in which consumer $\mathrm{i}$ owns a used unit at the beginning of the period, the consumer maintains the unit if $r_{i t}{ }^{U} r^{*}$ and purchases a new unit if $r_{i t}{ }^{U} r^{*}$. Fourth, in any period $t$ in which individual i consumes a used unit the individual purchases one unit of service and $\mathrm{r}_{\mathrm{it}}^{\mathrm{U}}$ units of replacement parts.

We now analyze the case in which each durable-goods producer cannot commit to future prices for new units, but has the option of monopolizing the maintenance market for its own product at the beginning of each period. Below we present and prove Proposition $4^{\#}$, which contains details that are not presented in Proposition 4 in the paper. Let $\mathrm{EU}_{\mathrm{i}}^{\mathrm{M}}$ denote the present discounted value evaluated in the period the consumer is born of the expected net benefits received by consumer $\mathrm{i}$ in this case. Also, $\mathrm{p}_{\mathrm{jt}} \mathrm{U}(\mathrm{r})$ denotes the price that durable-goods producer $\mathrm{j}$ charges in period $\mathrm{t}$ for one unit of service and $\mathrm{r}$ units of replacement parts to individuals who own used units of the firm's product at the beginning of period $t$.

Proposition $4^{\#}$ : Suppose each firm cannot commit in the first period to the prices it will charge in subsequent periods for a new unit of output, but each firm has the option of monopolizing the maintenance market for its own product at the beginning of each period. Then every equilibrium is characterized by i) through vi), where in each equilibrium every durable-goods producer monopolizes the maintenance market for its own product in every period $t, t \geq 1$.

i) For every firm $\mathrm{j}$ and period $\mathrm{t}, \mathrm{P}_{\mathrm{jt1}}{ }^{\mathrm{M}}=\mathrm{P}^{+}<\mathrm{c}+\mathrm{c}_{\mathrm{s}}$ and $\mathrm{P}_{\mathrm{jt} 2}{ }^{\mathrm{M}}=\mathrm{P}_{\mathrm{jt} 3}{ }^{\mathrm{M}}=\mathrm{P}^{+}+\Delta$.

ii) For every firm $j$ and period $t, p_{j t}{ }^{U}(r)=P^{+}+\Delta$ for all $r<r^{*}, p_{j t}{ }^{U}(r)>P^{+}+\Delta$ for all $r>r^{*}$, and $\mathrm{p}_{\mathrm{jt}}^{\mathrm{U}}(\mathrm{r}) \geq \mathrm{P}^{+}+\Delta$ for $\mathrm{r}=\mathrm{r}^{*}$.

iii) Each consumer $\mathrm{i}$ born in period $\mathrm{t}$ for whom $\mathrm{v}_{\mathrm{i}}>\mathrm{v}_{\mathrm{L}} *\left(\mathrm{v}_{\mathrm{i}} \leq \mathrm{v}_{\mathrm{L}}{ }^{*}\right)$ purchases a new unit in period $\mathrm{t}$ (never purchases new units, used units, or maintenance).

iv) In each period $t^{\prime}, t^{\prime}>t$, each consumer $i$ born in period $t$ for whom $v_{i}>v_{L} *$ and who does not own a used unit at the beginning of the period purchases a new unit from firm $\mathrm{j}_{\mathrm{it}}$.

v) In each period $t^{\prime}, t^{\prime}>t$, each consumer $i$ born in period $t$ who does own a used unit at the beginning of the period purchases a new unit from firm $j_{\text {it }}$ if $r_{i t^{\prime}}^{\mathrm{U}_{>}}>\mathrm{r}^{*}$, purchases one unit of service and $r_{i t^{\prime}}{ }^{\mathrm{U}}$ units of maintenance from firm $\mathrm{j}_{\mathrm{it}}$ if $\mathrm{r}_{\mathrm{it}} \mathrm{U}^{\mathrm{U}}<\mathrm{r}^{*}$, and chooses one of these two 
behaviors if $\mathrm{r}_{\mathrm{it}}^{\mathrm{U}}=\mathrm{r}^{*}$.

vi) $\mathrm{EU}_{\mathrm{i}}^{\mathrm{M}}=\mathrm{EU}_{\mathrm{i}}{ }^{*}$ for all $\mathrm{i}$.

Proof of Proposition 4 $4^{\#}$ : First note that, as proved in the proof of Proposition 4 in the paper, there does not exist an equilibrium in which a firm sells a strictly positive amount of new units in a certain period and does not monopolize the maintenance market in the next period. Given this, let $\mathrm{m}^{\mathrm{U}} \equiv \mathrm{c}_{\mathrm{s}}+\mathrm{r}^{\mathrm{U}} \mathrm{c}_{\mathrm{r}}$. Also, define $\mathrm{f}($.$) by \mathrm{f}\left(\mathrm{c}_{\mathrm{s}}+\mathrm{r}^{\mathrm{U}} \mathrm{c}_{\mathrm{r}}\right)=\mathrm{h}\left(\mathrm{r}^{\mathrm{U}}\right)$ for all $\mathrm{r}^{\mathrm{U}} \in(0, \infty)$ and $\mathrm{f}\left(\mathrm{c}_{\mathrm{s}}+\mathrm{r}^{\mathrm{U}} \mathrm{c}_{\mathrm{r}}\right)=0$ for all $\mathrm{r}^{\mathrm{U}}$ outside this interval, and define $\mathrm{r}^{*}$ by $\mathrm{m}^{*} \equiv \mathrm{c}_{\mathrm{s}}+\mathrm{r}^{*} \mathrm{c}_{\mathrm{r}}$. Then, the proof of Proposition 2 implies Proposition $4^{\#}$. Q.E.D. 